\section{RMD Open}

Rheumatic \&

Musculoskeletal Diseases

\title{
Association between glucocorticoid therapy and incidence of diabetes mellitus in polymyalgia rheumatica and giant cell arteritis: a systematic review and meta-analysis
}

To cite: Lai LYH, Harris E, West RM, et al. Association between glucocorticoid therapy and incidence of diabetes mellitus in polymyalgia rheumatica and giant cell arteritis: a systematic review and meta-analysis. RMD Open 2018:4:e000521. doi:10.1136/ rmdopen-2017-000521

- Prepublication history and additional material for this paper are available online. To view these files, please visit the journal online (http://dx.doi. org/10.1136/rmdopen-2017000521).

Received 14 July 2017 Revised 30 0ctober 2017 Accepted 26 November 2017

Check for updates

'Leeds Institute of Rheumatic and Musculoskeletal Medicine, University of Leeds, Leeds, UK ${ }^{2}$ Centre for Applied Research in Health, School of Human and Health Sciences, University of Huddersfield, Huddersfield, UK ${ }^{3}$ Leeds Institute of Health Sciences, University of Leeds, Leeds, UK

Correspondence to Lana Yin Hui Lai; umll@leeds.ac.uk

\section{ABSTRACT}

Background Polymyalgia rheumatica (PMR) and giant cell arteritis (GCA) are almost always treated with glucocorticoids (GCs), but long-term GC use is associated with diabetes mellitus (DM). The absolute incidence of this complication in this patient group remains unclear.

Objective To quantify the absolute risk of GC-induced DM in PMR and GCA from published literature.

Methods We identified literature from inception to February 2017 reporting diabetes following exposure to oral GC in patients with PMR and/or GCA without preexisting diabetes. A random-effects meta-analysis was performed to summarise the findings.

Results 25 eligible publications were identified. In studies of patients with GCA, mean cumulative GC dose was almost 1.5 times higher than in studies of PMR $(8.2 \mathrm{~g}$ vs $5.6 \mathrm{~g}$ ), with slightly longer treatment duration and longer duration of follow-up ( 6.4 years vs 4.4 years). The incidence proportion (cumulative incidence) of patients who developed new-onset DM was $6 \%(95 \% \mathrm{Cl} 3 \%$ to $9 \%)$ for PMR and $13 \%$ (95\% Cl 9\% to 17\%) for GCA. Based on UK data on incidence rate of DM in the general population, the expected background incidence rate of DM over 4.4 years in patients with PMR and 6.4 years in patients with GCA (follow-up duration) would be $4.8 \%$ and $7.0 \%$, respectively. Heterogeneity between studies was high $\left(I^{2}=79.1 \%\right)$, as there were differences in study designs, patient population, geographical locations and treatment. Little information on predictors of DM was found.

Conclusion Our meta-analysis produced plausible estimates of DM incidence in patients with PMR and GCA, but there is insufficient published data to allow precise quantification of DM risk.

\section{INTRODUCTION}

Polymyalgia rheumatica (PMR) is a glucocorticoid (GC)-responsive condition causing bilateral shoulder and pelvic girdle pain and stiffness in older people. ${ }^{1} \mathrm{PMR}$ is one of the most common reasons for long-term GC treatment in the community. ${ }^{2-4}$ Giant cell arteritis (GCA) is also treated with long-term

\section{Key messages}

What is already known about this subject?

- Polymyalgia rheumatica (PMR) and giant cell arteritis (GCA) are inflammatory disorders of the elderly, with glucocorticoids (GC) being the treatment of choice.

- Chronic use of GC is associated with diabetes mellitus (DM), though the absolute risk of developing DM is unclear.

What does this study add?

- Our meta-regression suggests that the incidence proportion (cumulative incidence) of patients who developed new-onset DM was 6\% $(95 \% \mathrm{Cl} 3 \%$ to $9 \%$ ) for PMR and $13 \%(95 \% \mathrm{Cl} 9 \%$ to $17 \%$ ) for $\mathrm{GCA}$, which is plausible, though there is insufficient published data to allow precise quantification of DM risk.

How might this impact on clinical practice?

- Findings from this study underline the importance of screening for GC-induced DM in patients with GCA/PMR in clinical practice and can also help inform dietary and lifestyle advice in patients taking GCs for GCA or PMR.

GCs, but at higher doses, ${ }^{5}$ and is the most common primary systemic vasculitis affecting individuals aged over 50 years. The UK incidence of PMR is $8.4 / 10000$ person-years ${ }^{2}$ and of GCA is 2.2/10 000 person-years. ${ }^{6}$ Both diseases have a female:male ratio of $2-3: 1^{15}$ and similar age distribution, with incidence peaking in the eighth decade of life. This age group is particularly vulnerable to the adverse effects of GC, which relate both to dose and duration of therapy ${ }^{7}$; the majority of patients with PMR and GCA experience GC-associated adverse effects. ${ }^{8}$ The most worrisome of these for both patients and rheumatologists is 


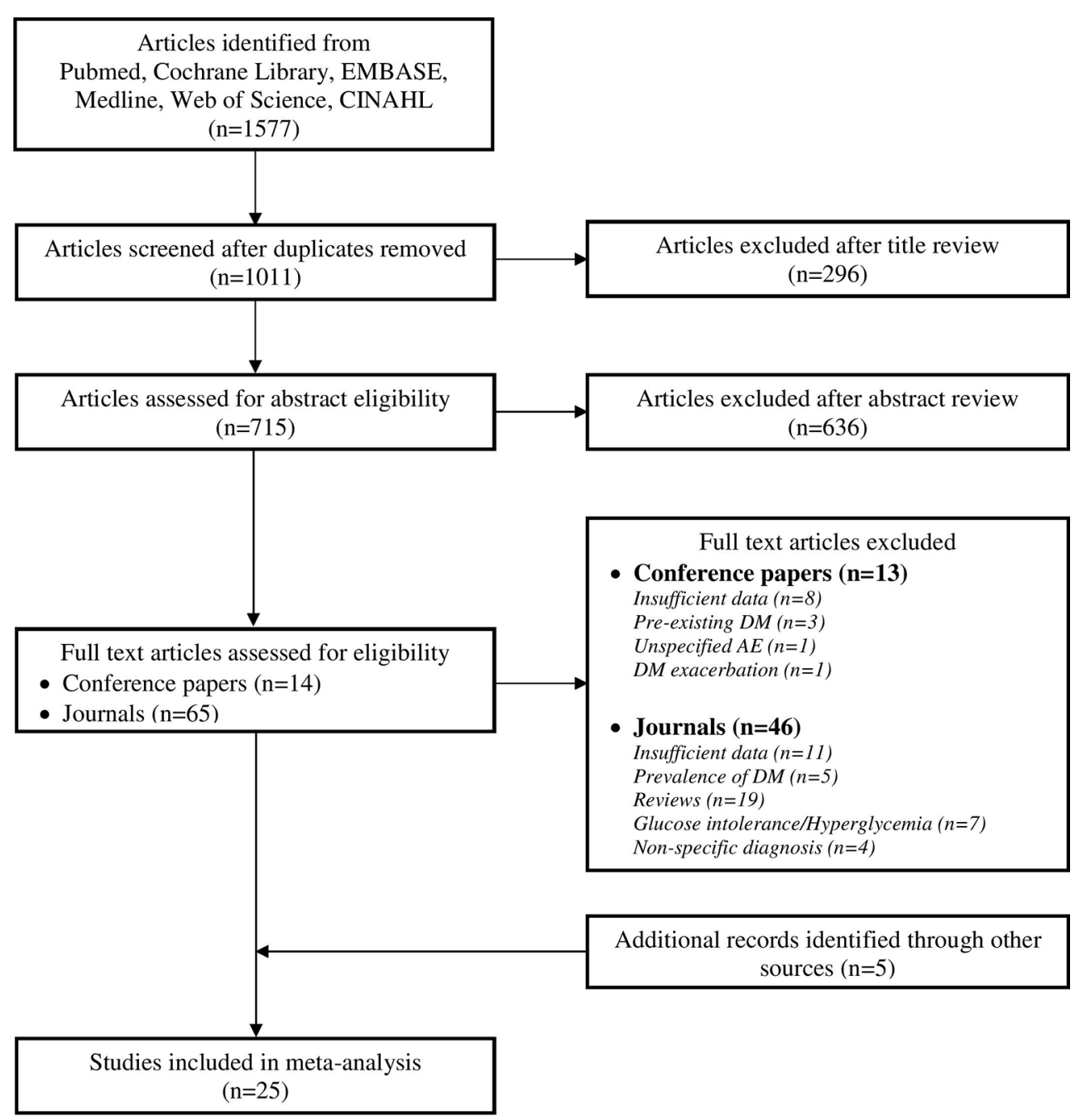

Figure 1 Flow chart of the selection process of studies. CINAHL, Cumulative Index of Nursing and Allied Health Literature.

diabetes mellitus (DM) ${ }^{9}$ Long-standing DM is associated with complications such as chronic kidney disease, retinopathy, diabetic neuropathy and so on, which often lead to a decline in quality of life, as well as marked shortening of life expectancy. This is also significant from a health economic perspective as it incurs significant additional healthcare utilisation. Despite the importance of this for patients, physicians and payers, there is currently minimal information on what the absolute risk of diabetes is in this particular patient group and which patients are at the greatest risk of developing new-onset diabetes while taking GC for PMR or GCA. Quantification of the costs and burdens of GC adverse effects allows assessment of the benefit of new therapies intended to reduce GC exposure while maintaining disease control. ${ }^{10}$

It is recommended that clinicians take comorbidity and prognostic risk factors into account when making treatment decisions, ${ }^{15}$ but as regards for risk of DM, clinicians must rely on indirect evidence extrapolated from other populations, such that the strength of the evidence for this would need to be downgraded for clinical guidelines. ${ }^{15}$ We aimed to collate published literature that could help to answer this question.

\section{METHODS}

\section{Search strategy}

We searched for published studies or conference abstracts indexed in PubMed, Ovid (Medline and Embase), Web of Science, Cochrane Library and Cumulative Index of Nursing and Allied Health Literature from inception to February 2017. The search included terms for patients with PMR and/or GCA who were prescribed oral GC therapy, as well as diabetes-related terms as some individuals eventually developed diabetes. The full search strategy is available in online supplementary appendix 1. We also manually screened reference lists of selected retrieved articles to identify further papers that may have been missed in the database search. We made every effort to include all available studies and conference abstracts (regardless of publication year), which included contacting the first authors by email if necessary. The selection process of identifying relevant studies is shown in figure 1 .

\section{Eligibility criteria}

We identified original research articles, conference abstracts and grey literature that reported diabetes 
Table 1 Studies included in the meta-analysis

\begin{tabular}{|c|c|c|c|c|}
\hline First author, publication year & Country & Population & Study design & $\begin{array}{l}\text { Start of study } \\
\text { enrolment }\end{array}$ \\
\hline von Knorring, $1979^{36}$ & Finland & PMR & Observational & 1967 \\
\hline Godeau, $1982^{37}$ & France & GCA & Observational & 1966 \\
\hline Chuang, $1982^{38}$ & USA & PMR & Observational & 1970 \\
\hline Behn, $1983^{39}$ & UK & PMR & Observational & 1968 \\
\hline Gouet, $1985^{40}$ & France & GCA & Observational & 1970 \\
\hline Andersson, $1986^{41}$ & Sweden & GCA & Observational & 1968 \\
\hline Delecoeuillerie, $1988^{42}$ & France & GCA & Observational & 1976 \\
\hline Nesher, $1994^{43}$ & Israel & GCA & Observational & 1978 \\
\hline Gabriel, $1997^{44}$ & USA & PMR & Observational & 1970 \\
\hline Jover, $2001^{8}$ & Spain & GCA & $\mathrm{RCT}$ & 1993 \\
\hline Proven, $2003^{45}$ & USA & GCA & Observational & 1950 \\
\hline Hutchings, $2007^{46}$ & UK & PMR & Observational & 2001 \\
\hline Salvarani, $2007^{47}$ & Italy & PMR & $\mathrm{RCT}$ & 2003 \\
\hline Cimmino, $2008^{48}$ & Italy & PMR & RCT & 1998 \\
\hline Schmidt, $2008^{49}$ & Germany & GCA & Observational & 1997 \\
\hline Dasgupta, $2009^{50}$ & UK & PMR & Observational & 2001 \\
\hline Khalifa, $2009^{51}$ & Tunisia & GCA & Observational & 1986 \\
\hline Martinez-Lado, $2011^{52}$ & Spain & GCA & Observational & 1992 \\
\hline Mazzantini, $2012^{53}$ & Italy & PMR & Observational & 1997 \\
\hline Dunstan, $2014^{54}$ & Australia & GCA & Observational & 1991 \\
\hline Alba, $2014^{55}$ & Spain & GCA & Observational & 1995 \\
\hline Seror, $2014^{56}$ & France & GCA & RCT & 2006 \\
\hline Muller, $2016^{57}$ & France & GCA & Observational & 2002 \\
\hline Carbonella, $2016^{58}$ & Italy & GCA & Observational & NA \\
\hline Faurschou, $2017^{31}$ & Denmark & GCA & Observational & 1997 \\
\hline
\end{tabular}

GCA, giant cell arteritis; PMR, Polymyalgia rheumatica; RCT, randomised controlled trial.

following exposure to oral GC therapy. The populations of interest were patients with a diagnosis of PMR and/or GCA with no pre-existing diabetes (supplementary appendix 4). We assume that, if not otherwise stated, all patients with PMR or GCA were treated with GCs. We included all randomised controlled trials, cohort studies, cross-sectional studies and case-control studies. Case series and case reports were excluded. There was no language restriction. Non-English articles were translated with the help of Google Translate and colleagues who were native speakers of the respective languages.

\section{Study selection}

Two investigators (LYHL and EH) independently carried out the initial screening of search results by title and abstract, using the abstract screener software 'Abstrackr"'11 and Endnote X7.4 (1988-2015 Thomson Reuters). Study eligibility was determined independently, and any disagreements were resolved by consensus with the third investigator (SLM).

\section{Data extraction}

Data were extracted independently by LYHL and EH using a standardised data collection Microsoft Access database. Any discrepancies in data extraction were resolved by consensus. For articles containing more than one study group, we included the 'GC-only' arm and excluded the groups where there was another study drug in addition to GCs. We also performed a sensitivity analysis by incorporating all the study groups into our analysis. Information extracted included journal information, publication year, year of enrolment, study design, patient demographics (age, sex, body mass index, weight, height, medical history, family history, glucose level and HbA1c), number of patients recruited, number of patients with DM, definition of DM, GC indication, treatment dose and duration and duration of follow-up. Patient populations were classified as 'PMR' or 'GCA' based on their primary diagnosis as determined by the authors. We only included studies where the authors identified 'new-onset diabetes' associated with GC use. We excluded any prediabetic states 
Table 2 Summary characteristics of individuals with PMR and/or GCA

\begin{tabular}{llll}
\hline & Total $(\mathbf{n = 3 7 4 3 )}$ & PMR (n=920) & $\begin{array}{l}\text { GCA } \\
(\mathbf{n}=2823)\end{array}$ \\
\hline $\begin{array}{l}\text { Demographics } \\
\begin{array}{l}\text { Age at } \\
\text { baseline* } \\
\text { years }\end{array}\end{array}$ & $74.1(3.6)$ & $71.6(3.1)$ & $74.9(3.7)$ \\
$\begin{array}{l}\text { \% Female } \\
\text { Glucocorticoids }\end{array}$ & $67.8(10.6)$ & $71.0(10.7)$ & $66.7(10.5)$ \\
$\begin{array}{l}\text { use } \\
\text { Cumulative } \\
\text { dose, g }\end{array}$ & $7.6(4.2)$ & $5.6(3.3)$ & $8.2(4.5)$ \\
$\begin{array}{l}\text { Duration } \\
\text { of GC use, } \\
\text { years }\end{array}$ & $2.4(1.5)$ & $2.1(1.2)$ & $2.5(1.6)$ \\
$\begin{array}{l}\text { Follow-up } \\
\text { Duration, } \\
\text { years }\end{array}$ & $5.9(4.1)$ & $4.4(3.3)$ & $6.4(4.4)$ \\
\hline
\end{tabular}

All data are presented as a weighted mean (SD) across studies. ${ }^{*}$ Age at diagnosis $(n=11)$, age at study inclusion $(n=3)$, age unspecified in study $(n=11)$.

(eg, increased fasting glucose and glucose intolerance) or exacerbation of pre-existing diabetes (eg, worsened diabetes and addition of insulin).

\section{Statistical analysis}

The incidence proportion (cumulative incidence) of new DM cases was modelled using binomial regression where the outcome variable was the number of DM cases given the number of GC-treated patients. The candidate explanatory variables included were: mean age, proportion of females, year of enrolment, diagnosis (PMR or GCA), cumulative dose and treatment duration. Variables were clinically prioritised for inclusion in the multivariable modelling rather than taking a purely data-driven approach. Results were presented as OR and 95\% CI. We carried out a meta-analysis using a random-effects model. Statistical analysis was done with $\mathrm{R}$ (V.3.3.1.). ${ }^{12}$ The Meta-analysis of Observational Studies in Epidemiology reporting guidelines ${ }^{13}$ was used as a checklist (online supplementary appendix 2) to ensure proper evaluation of quality and completeness, and the risk of bias for both observational studies and RCTs were assessed using the Cochrane Collaboration tool for assessing risk of bias. ${ }^{14}$ The risk of bias assessment was done independently by authors and discrepancies were resolved by consensus.

\section{RESULTS}

Our systematic literature search identified 25 eligible publications consisting of 24 journal articles and 1 conference abstract. Of the final 25 studies, 21 were cohort studies and 4 were RCTs; 9 studies reported on predominantly PMR patients, while 16 studies reported predominantly GCA patients. Nine of the 16 studies we classified as GCA studies included some patients with polymyalgic symptoms. Four of the nine studies we classified as PMR studies included some patients who also had been diagnosed with GCA, but we decided to classify them as PMR studies because that was the primary diagnosis as determined by the authors.

Most of the studies were conducted in Europe $(n=20)$, followed by USA $(n=3)$, Australia $(n=1)$ and Tunisia $(\mathrm{n}=1)$. A total of 19 studies started enrolment before the year 2000, the earliest commencing study enrolment in 1950. Details of the individual studies are shown in table 1 .

The weighted mean age across the studies reviewed was 71.6 years for PMR and 74.9 years for GCA, with approximately two-thirds being female (table 2). Cumulative dose in the GCA group was higher than the PMR group, with longer treatment duration and follow-up as well.

Of the 25 studies, prednisone was used in 15 studies and prednisolone in 8 studies. Patients from one study were on 6-methylprednisolone, and one study did not specify the type of GC used.

The incidence proportion of patients with PMR who developed new-onset DM was 6\% (95\% CI 3\% to 9\%) and the incidence proportion of patients with GCA who developed new-onset DM was $13 \%$ (95\% CI 9\% to 17\%) (figure 2). Six studies reported a newly diagnosed DM during follow-up, 1 during GC treatment and 18 studies did not specify when DM was diagnosed.

We also performed a sensitivity analysis by incorporating all the study groups into our analysis, of which it did not alter our results (data not shown).

We combined both statistical and clinical considerations to select the most parsimonious clinically relevant model to explore the predictors of GC-induced DM. In our study, the risk of developing new-onset DM among patients with GCA was doubled the risk of patients with PMR (online supplementary appendix 3), which was also reflected in our meta-regression results $(13 \%$ vs $6 \%$, respectively).

Most RCT studies scored a low risk in most domains; in some cases, however, we were unable to assess the risk of bias due to insufficient information (table 3 ).

The overall risk of bias was high for many of the observational studies, especially for domains relating to the outcome and prognostic variables (table 4). DM was not precisely defined in the studies, and there was a lack of uniformity on how it was measured. Of the 25 studies, only six included an a priori definition of DM. Even with these six studies, various measurement methods were used, ranging from random blood sugar estimations to fasting plasma glucose levels to use of pharmacological interventions such as oral antidiabetic drugs and insulin. In 13 articles (52\%), adjustment and assessment of prognostic variables were not well accounted for. 
Study

Population $=$ PMR

von Knorring J 1979

Behn AR 1983

Chuang TY 1982

Gabriel SE 1997

Salvarani C 2007

Hutchings A 2007

Cimmino MA 2008

Mazzantini M 2012

Dasgupta B 2009

Random effects model

Heterogeneity: 1 -squared $=66.8 \%$, tau-squared $=0.4482, \rho=0.0022$

Population $=\mathrm{GCA}$

Delecoeuillerie G 1988

Andersson R 1986

Gouet D 1985

Godeau P 1982

Nesher G 1994

Jover JA 2001

Proven A 2003

Schmidt WA 2008

Khalifa M 2009

Luciana ML 2011

Dunstan E 2013

Alba MA 2014

Seror R 2014

Muller G 2016

Carbonella A 2016

Farschou M 2016

Random effects model

Reteromeity: $t$ squared

Random effects model

Heterogeneity: 1 -squared $=79.1 \%$, tau-squared

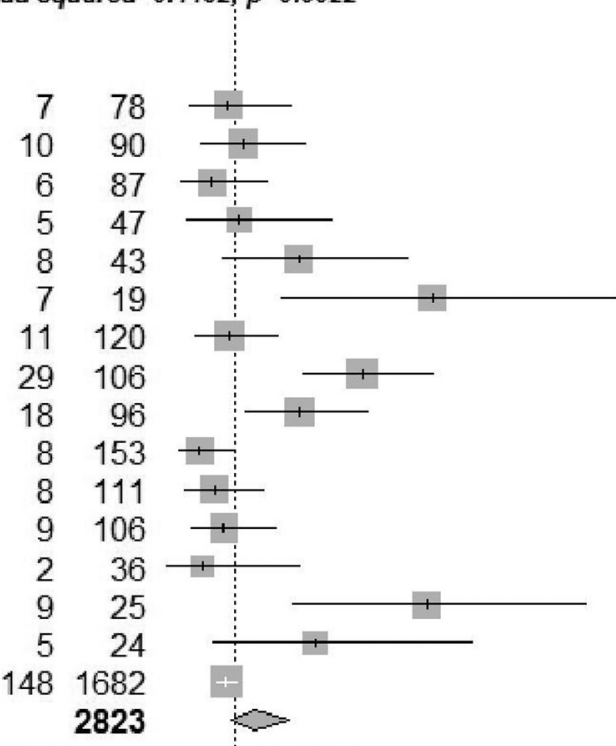

2823
Events Total

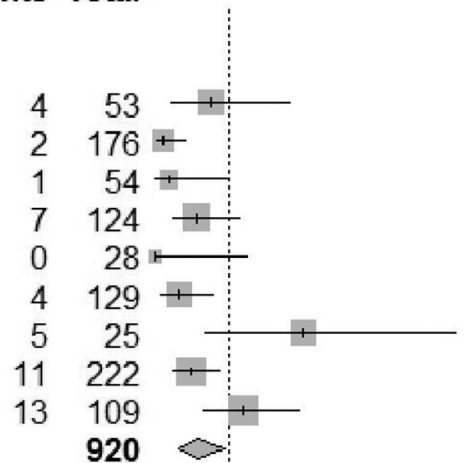

Proportion

$95 \%-\mathrm{Cl}$ W(random)

$\begin{array}{ll}0.08[0.02 ; 0.18] & 3.6 \% \\ 0.01[0.00 ; 0.04] & 2.6 \% \\ 0.02[0.00 ; 0.10] & 1.7 \% \\ 0.06[0.02 ; 0.11] & 4.3 \% \\ 0.00[0.00 ; 0.12] & 1.0 \% \\ 0.03[0.01 ; 0.08] & 3.6 \% \\ 0.20[0.07 ; 0.41] & 3.7 \% \\ 0.05[0.02 ; 0.09] & 4.8 \% \\ 0.12[0.07 ; 0.20] & 4.9 \% \\ \mathbf{0 . 0 6}[\mathbf{0 . 0 3} ; \mathbf{0 . 0 9}] & \mathbf{3 0 . 1 \%}\end{array}$

$0.09[0.04 ; 0.18] \quad 4.3 \%$

$0.11[0.05 ; 0.19] \quad 4.6 \%$

$0.07[0.03 ; 0.14] \quad 4.1 \%$

$0.11[0.04 ; 0.23] \quad 3.8 \%$

$0.19[0.08 ; 0.33] \quad 4.3 \%$

$0.37[0.16 ; 0.62] \quad 3.8 \%$

$0.09[0.05 ; 0.16] \quad 4.8 \%$

$0.27[0.19 ; 0.37] \quad 5.3 \%$

$0.19[0.12 ; 0.28] \quad 5.1 \%$

$0.05[0.02 ; 0.10] \quad 4.5 \%$

$0.07[0.03 ; 0.14] \quad 4.5 \%$

$0.08[0.04 ; 0.16] \quad 4.6 \%$

$0.06[0.01 ; 0.19] \quad 2.6 \%$

$0.36[0.18 ; 0.57] \quad 4.2 \%$

$0.21 \quad[0.07 ; 0.42] \quad 3.6 \%$

$0.09[0.07 ; 0.10] \quad 5.9 \%$

$0.13[0.09 ; 0.17] \quad 69.9 \%$

$0.10[0.08 ; 0.13] \quad 100 \%$

Figure 2 Proportion of PMR and GCA patients who developed new-onset DM after GC use. GCA, giant cell arteritis; PMR, polymyalgia rheumatica.

\section{DISCUSSION}

There is overwhelming epidemiological and pathophysiological evidence that GC therapy may cause DM. ${ }^{15-19}$ Our aim was to estimate the effect size in this particular population for the purpose of informing clinical decisions about care of patients with PMR/GCA and health economic analyses about the cost-effectiveness of new therapies for PMR/GCA. In our meta-analysis of published literature, the estimated incidence proportion (cumulative incidence) of new-onset diabetes was

Table 3 Risk of bias of randomised controlled trials

\begin{tabular}{|c|c|c|c|c|c|c|}
\hline & $\begin{array}{l}\text { Random } \\
\text { sequence } \\
\text { generation } \\
\text { (selection bias) }\end{array}$ & $\begin{array}{l}\text { Allocation } \\
\text { concealment } \\
\text { (selection bias) }\end{array}$ & $\begin{array}{l}\text { Blinding of } \\
\text { participants } \\
\text { and personnel } \\
\text { (performance } \\
\text { bias) }\end{array}$ & $\begin{array}{l}\text { Blinding of } \\
\text { outcome } \\
\text { assessment } \\
\text { (detection bias) }\end{array}$ & $\begin{array}{l}\text { Incomplete } \\
\text { outcome data } \\
\text { (attrition bias) }\end{array}$ & $\begin{array}{l}\text { Selective } \\
\text { reporting } \\
\text { (reporting bias) }\end{array}$ \\
\hline Jover et al ${ }^{8}$ & L & U & $\mathrm{L}$ & $\mathrm{U}$ & L & $L$ \\
\hline Salvarani et al ${ }^{47}$ & L & L & L & L & L & $U$ \\
\hline Cimmino et $\left.\mathrm{a}\right|^{48}$ & L & U & $\mathrm{L}$ & L & L & U \\
\hline Seror et al ${ }^{56}$ & L & L & L & L & $\mathrm{H}$ & U \\
\hline
\end{tabular}

$\mathrm{H}$, high risk of bias; L, lower risk of bias; $\mathrm{U}$, unclear risk of bias. 
Table 4 Risk of bias of observational studies

\begin{tabular}{|c|c|c|c|c|c|c|c|}
\hline & $\begin{array}{l}\text { Similar } \\
\text { population }\end{array}$ & $\begin{array}{l}\text { Assessment } \\
\text { of exposure }\end{array}$ & $\begin{array}{l}\text { Outcome not } \\
\text { present at } \\
\text { start of study }\end{array}$ & $\begin{array}{l}\text { Adjustment } \\
\text { of } \\
\text { prognostic } \\
\text { variables }\end{array}$ & $\begin{array}{l}\text { Assessment } \\
\text { of } \\
\text { prognostic } \\
\text { variables }\end{array}$ & $\begin{array}{l}\text { Assessment } \\
\text { of outcome }\end{array}$ & $\begin{array}{l}\text { Adequate } \\
\text { follow-up }\end{array}$ \\
\hline von Knorring et $a l^{36}$ & ++ & + & - & -- & -- & - & + \\
\hline Chuang et $\left.a\right|^{38}$ & + & ++ & -- & -- & ++ & -- & + \\
\hline Godeau et $a l^{37}$ & - & - & -- & -- & -- & -- & -- \\
\hline Behn et $\left.a\right|^{39}$ & ++ & ++ & -- & -- & -- & -- & + \\
\hline Gouet et a $/^{40}$ & + & + & -- & -- & -- & -- & + \\
\hline Andersson et $a l^{41}$ & ++ & ++ & -- & -- & -- & -- & + \\
\hline Delecoeuillerie et $a{ }^{42}$ & ++ & ++ & -- & -- & -- & -- & + \\
\hline Nesher et al ${ }^{43}$ & ++ & ++ & -- & - & + & -- & + \\
\hline Gabriel et $\left.a\right|^{44}$ & ++ & ++ & + & + & ++ & ++ & + \\
\hline Proven et al ${ }^{45}$ & ++ & ++ & + & + & ++ & ++ & + \\
\hline Hutchings et $a l^{46}$ & ++ & ++ & -- & + & + & + & -- \\
\hline Schmidt et a/49 & ++ & ++ & - & + & + & -- & - \\
\hline Dasgupta et a $\left.\right|^{50}$ & + & - & - & -- & -- & -- & + \\
\hline Khalifa et $a l^{51}$ & + & + & -- & -- & -- & -- & -- \\
\hline Martinez-Lado et $a^{52}$ & + & ++ & -- & + & ++ & -- & + \\
\hline Mazzantini et al ${ }^{53}$ & ++ & ++ & ++ & + & + & ++ & + \\
\hline Dunstan et $\left.a\right|^{54}$ & ++ & ++ & + & ++ & + & -- & + \\
\hline Alba et $a l^{55}$ & ++ & ++ & + & ++ & -- & + & + \\
\hline Carbonella et $a^{58}$ & + & -- & -- & -- & -- & -- & - \\
\hline Farschou et $\left.a\right|^{31}$ & ++ & ++ & + & - & ++ & ++ & ++ \\
\hline Muller et $\left.a\right|^{57}$ & ++ & + & -- & -- & + & -- & - \\
\hline
\end{tabular}

Question 1: was selection of exposed and non-exposed cohorts drawn from the same population? Question 2: can we be confident in the assessment of exposure? Question 3: can we be confident that the outcome of interest was not present at start of study? Question 4: did the study match exposed and unexposed for all variables that are associated with outcome of interest or did the statistical analysis adjust for these prognostic variables? Question 5: can we be confident in the assessment of the presence or absence of prognostic factors? Question 6: can we be confident in the assessment of outcome? Question 7: was the follow up of cohorts adequate? ++ , definitely yes (low risk of bias); +, probably yes; -, probably no; --, definitely no (high risk of bias).

$6 \%(95 \%$ CI $3 \%$ to $9 \%)$ for patients with PMR and $13 \%$ (95\% CI 9\% to 17\%) for patients with GCA. These figures are plausible: they are slightly higher than current UK population rates for patients of this age and sex, of which the expected background incidence rate of DM over 4.4 years in patients with PMR and 6.4 years in patients with GCA (follow-up duration) would be $4.8 \%$ and $7.0 \%$, respectively. ${ }^{20}$ It should also be noted that many of the studies we reviewed were conducted at a time when population incidence of DM was lower than it is now. ${ }^{20}$ In addition, a few studies, ${ }^{21-25}$ including a recent meta-analysis, ${ }^{26}$ have shown that patients with GCA had a lower prevalence of DM at the time of GCA diagnosis compared with age-matched and sex-matched controls, which may suggest that the magnitude of GC-induced DM to be greater than expected. Two observational studies ${ }^{2728}$ found no difference in pre-existing DM between patients with GCA and their comparison patients, while another two studies ${ }^{2930}$ reported a higher prevalence of DM in the GCA cohort.
A very recent Danish study ${ }^{31}$ reported that the incidence risk ratio of new-onset DM was 7.0 (95\% CI 5.2 to 9.3) in the GCA cohort during the first year of observation when compared with the general population. Beyond the first year, they reported that the incidence rates for DM were not significantly increased. In another large observational study of 5011 patients with GCA, the incidence risk ratios of DM was 1.4 (95\% CI 1.2 to 1.7 ) as compared with matched non-GCA patients. ${ }^{32}$ The median time for the occurrence of DM in the GCA group was 1 year, which supports the hypothesis that the risk of developing GC-induced DM may be highest within the first year of GC use. Other datasets emphasise cumulative dose: a very recently published US study reported that the risk for new-onset DM rose $5 \%$ with each $1000 \mathrm{mg}$ of GC exposure in patients with GCA. ${ }^{33}$

Heterogeneity in study design was high; the study populations were diverse in terms of disease manifestation, situated at different geographical locations and were also subjected to different treatment strategies. In 
addition, the studies included in this meta-analysis were done over a span of 40 years, during which time clinical practice is likely to have changed. This heterogeneity was also reflected in high statistical heterogeneity identified by our meta-analysis as assessed by the $\mathrm{I}^{2}$ and tau-squared, the DerSimonian-Laird estimate derived from a random effects model. One particular difficulty was the lack of clarity and consistency regarding the definition of DM in the studies identified. It was also difficult to identify the onset of DM as most of the studies (72\%) did not specify whether DM developed during GC treatment or during the follow-up period.

Since most of the studies reviewed did not have the primary aim of quantifying DM risk in PMR/GCA, the detail available in published reports was limited. For example, summary measures such as mean starting dose, mean treatment duration and mean cumulative dose cannot fully capture the pattern of GC dosing used for PMR/GCA, where the highest GC burden occurs during the first 3 months. ${ }^{1534}$

Because GCs are the mainstay of treatment for PMR and GCA, it was not possible to disentangle the effect of the disease from the effect of the treatment. It is however known that systemic inflammation itself can also induce a state of insulin resistance, ${ }^{735}$ so it is plausible that the inflammatory disease itself (PMR or GCA) could have contributed to the risk of new-onset DM. In addition, some medications commonly prescribed to elderly patients may contribute to the risk of DM (eg, thiazide diuretics, beta-blockers, niacins and statins). These were not reported by the studies identified, as their primary focus was not on DM.

Confounding by indication could not be excluded. For example, for the observational studies, clinicians may have been less willing to prescribe higher GG doses to control disease activity in obese patients at high risk of DM. We were also unable to exclude spurious association due to a possible detection/screening bias; longitudinally collected individual patient data would have been informative in this regard.

The overall risk of bias was high for many of the observational studies, especially for domains relating to the outcome and prognostic variables. Therefore, results should be interpreted with caution.

It is possible that studies that did not look for diagnoses of DM or found no cases of new onset DM would not have mentioned diabetes and therefore have been excluded from our search. This could have led to an overestimate in the incidence of DM. Since DM has long been a concern with GC therapy, however, this is unlikely.

Our attempt to identify predictors of DM in this meta-analysis is more exploratory in nature as there are some limitations in the multivariable modelling. With this limited dataset and large number of potential explanatory variables, there is a risk of overfitting and may limit generalisability of this model. Other limitations of the model include the assumption that there is a linear relationship between variables, but it is also possible that collinearity may exist among some of the predictor variables. We excluded follow-up duration in our analysis because there is a high possibility that follow-up duration was confounded with diagnosis since patients with GCA are more likely to receive higher GC doses, thus tend to be monitored over a longer period of time.

\section{CONCLUSION}

Findings from this study underline the importance of screening for GC-induced DM in patients with GCA/ PMR in clinical practice ${ }^{15}$ and can also help inform dietary and lifestyle advice in patients taking GC for GCA or PMR. As well as limitations inherent to the meta-analysis itself, there remains considerable uncertainty in our estimate of the absolute risk of DM in PMR/GCA, since most published studies were not conducted with this as the primary aim. Furthermore, there is virtually no direct evidence as to which patients are at the greatest risk of DM, which would inform decisions as to how treatment should be individualised. We suggest that further research should analyse individual patient data within large datasets to generate clinically useful evidence to inform the next generation of clinical guidelines .

Acknowledgements We would like to thank Dr Claire Wenhem for her contribution in assessing the risk of bias for the French article. We would also like to acknowledge prior presentation of this work at the EULAR Congress, with the following abstract: Lai L, Harris E, West R, et al. FRI0334 What is the absolute risk of developing diabetes mellitus in patients with glucocorticoid-treated polymyalgia rheumatica and giant cell arteritis? A systematic review and meta-analysis. Annals of the Rheumatic Diseases 2017; 76: 613.

Contributors Study conception: LYHL, SLM and RMW. Drafting the manuscript: LLYH, EH, RW, SM. Literature search \& data collection: LLYH, EH. Statistical analysis: LLYH, RW. Critical review of the manuscript for content: LLYH, EH, RW, SM. Study supervision: RW, SM.

Funding This research received no specific grant from any funding agency in the public, commercial or not-for-profit sectors.

Competing interests None declared.

Patient consent Not required.

Provenance and peer review Not commissioned; externally peer reviewed.

Data sharing statement No additional data are available.

Open Access This is an Open Access article distributed in accordance with the Creative Commons Attribution Non Commercial (CC BY-NC 4.0) license, which permits others to distribute, remix, adapt, build upon this work non-commercially, and license their derivative works on different terms, provided the original work is properly cited and the use is non-commercial. See: http://creativecommons.org/ licenses/by-nc/4.0/

C Article author(s) (or their employer(s) unless otherwise stated in the text of the article) 2018. All rights reserved. No commercial use is permitted unless otherwise expressly granted.

\section{REFERENCES}

1. Dejaco C, Singh YP, Perel P, et al. 2015 recommendations for the management of polymyalgia rheumatica: a European League Against Rheumatism/American College of Rheumatology collaborative initiative. Arthritis Rheumatol 2015;67:2569-80.

2. Smeeth L, Cook C, Hall AJ, et al. Incidence of diagnosed polymyalgia rheumatica and temporal arteritis in the United Kingdom, 1990-2001. Ann Rheum Dis 2006;65:1093-8. 
3. Vanhoof J, Declerck K, Geusens P, et al. Prevalence of rheumatic diseases in a rheumatological outpatient practice. Ann Rheum Dis 2002;61:453-5.

4. Walsh LJ, Wong CA, Pringle M, et al. Use of oral corticosteroids in the community and the prevention of secondary osteoporosis: a cross sectional study. BMJ 1996;313:344-6.

5. Dasgupta B, Borg FA, Hassan N, et al. BSR and BHPR guidelines for the management of giant cell arteritis. Rheumatology 2010;49:1594-7.

6. Salvarani C, Crowson CS, O'Fallon WM, et al. Reappraisal of the epidemiology of giant cell arteritis in Olmsted County, Minnesota, over a fifty-year period. Arthritis Rheum 2004;51:264-8.

7. Strehl C, Bijlsma JW, de Wit M, et al. Defining conditions where long term glucocorticoid treatment has an acceptably low level of harm to facilitate implementation of existing recommendations: viewpoints from an EULAR task force. Ann Rheum Dis 2016;75:952-7.

8. Jover JA, Hernández-García C, Morado IC, et al. Combined treatment of giant-cell arteritis with methotrexate and prednisone. a randomized, double-blind, placebo-controlled trial. Ann Intern Med 2001:134:106-14

9. van der Goes MC, Jacobs JW, Boers M, et al. Patient and rheumatologist perspectives on glucocorticoids: an exercise to improve the implementation of the European League Against Rheumatism (EULAR) recommendations on the management of systemic glucocorticoid therapy in rheumatic diseases. Ann Rheum Dis 2010;69:1015-21.

10. Villiger PM, Adler S, Kuchen S, et al. Tocilizumab for induction and maintenance of remission in giant cell arteritis: a phase 2, randomised, double-blind, placebo-controlled trial. Lancet 2016;387:1921-7.

11. Wallace BC, Small K, Brodley CE, et al. Deploying an interactive machine learning system in an evidence-based practice center: abstrackr. Proceedings of the ACM International Health Informatics Symposium (IHI), 2012:819-24.

12. R Development Core Team. R: A language and environment for statistical computing. Vienna, Austria: R Foundation for Statistical Computing, 2012.

13. Stroup DF, Berlin JA, Morton SC, et al. Meta-analysis of observational studies in epidemiology: a proposal for reporting. Meta-analysis Of Observational Studies in Epidemiology (MOOSE) group. JAMA 2000;283:2008-12.

14. Higgins JPT, Green S. Cochrane handbook for systematic reviews of interventions: The Cochrane Collaboration (Version 5.1.0).

15. Movahedi M, Beauchamp ME, Abrahamowicz M, et al. Risk of incident diabetes mellitus associated with the dosage and duration of oral glucocorticoid therapy in patients with rheumatoid arthritis. Arthritis Rheumatol 2016;68:1089-98.

16. Weinstein SP, Wilson CM, Pritsker A, et al. Dexamethasone inhibits insulin-stimulated recruitment of GLUT4 to the cell surface in rat skeletal muscle. Metabolism 1998;47:3-6.

17. Ruzzin J, Wagman AS, Jensen J. Glucocorticoid-induced insulin resistance in skeletal muscles: defects in insulin signalling and the effects of a selective glycogen synthase kinase-3 inhibitor. Diabetologia 2005;48:2119-30.

18. Strohmayer EA, Krakoff LR. Glucocorticoids and cardiovascular risk factors. Endocrinol Metab Clin North Am 2011;40:409-17.

19. van Raalte $\mathrm{DH}$, Brands $\mathrm{M}$, van der Zijl NJ, et al. Low-dose glucocorticoid treatment affects multiple aspects of intermediary metabolism in healthy humans: a randomised controlled trial. Diabetologia 2011;54:2103-12.

20. Sharma M, Nazareth I, Petersen I. Trends in incidence, prevalence and prescribing in type 2 diabetes mellitus between 2000 and 2013 in primary care: a retrospective cohort study. BMJ Open 2016;6:e010210.

21. Udayakumar PD, Chandran AK, Crowson CS, et al. Cardiovascular risk and acute coronary syndrome in giant cell arteritis: a population-based retrospective cohort study. Arthritis Care Res 2015;67:396-402

22. Matthews JL, Gilbert DN, Farris BK, et al. Prevalence of diabetes mellitus in biopsy-positive giant cell arteritis. J Neuroophthalmol 2012;32:202-6.

23. Gonzalez-Gay MA, Piñeiro A, Gomez-Gigirey A, et al. Influence of traditional risk factors of atherosclerosis in the development of severe ischemic complications in giant cell arteritis. Medicine 2004;83:342-7.

24. Schmidt J, Kermani TA, Muratore F, et al. Statin use in giant cell arteritis: a retrospective study. J Rheumatol 2013;40:910-5.

25. Duhaut P, Pinede L, Demolombe-Rague S, et al. Giant cell arteritis and cardiovascular risk factors: a multicenter, prospective casecontrol study. Groupe de Recherche sur l'Artérite à Cellules Géantes. Arthritis Rheum 1998;41:1960-5.
26. Ungprasert P, Upala S, Sanguankeo A, et al. Patients with giant cell arteritis have a lower prevalence of diabetes mellitus: A systematic review and meta-analysis. Mod Rheumatol 2016;26:410-4.

27. Li L, Neogi T, Jick S. Giant cell arteritis and vascular disease-risk factors and outcomes: a cohort study using UK Clinical Practice Research Datalink. Rheumatology 2017;56:kew482-62.

28. Tomasson G, Peloquin C, Mohammad A, et al. Risk for cardiovascular disease early and late after a diagnosis of giant-cell arteritis: a cohort study. Ann Intern Med 2014;160:73-80-80.

29. Pujades-Rodriguez M, Duyx B, Thomas SL, et al. Associations between polymyalgia rheumatica and giant cell arteritis and 12 cardiovascular diseases. Heart 2016;102:383-9.

30. Robson JC, Kiran A, Maskell J, et al. The relative risk of aortic aneurysm in patients with giant cell arteritis compared with the general population of the UK. Ann Rheum Dis 2015;74:129-35.

31. Faurschou M, Ahlström MG, Lindhardsen J, et al. Risk of diabetes mellitus among patients diagnosed with giant cell arteritis or granulomatosis with polyangiitis: comparison with the general population. J Rheumatol 2017;44:78-83.

32. Wilson JC, Sarsour K, Collinson N, et al. Incidence of outcomes potentially associated with corticosteroid therapy in patients with giant cell arteritis. Semin Arthritis Rheum 2017;46:650-6.

33. Broder MS, Sarsour K, Chang E, et al. Corticosteroid-related adverse events in patients with giant cell arteritis: A claims-based analysis. Semin Arthritis Rheum 2016;46:246-52.

34. Matteson EL, Buttgereit F, Dejaco C, et al. Glucocorticoids for management of polymyalgia rheumatica and giant cell arteritis. Rheum Dis Clin North Am 2016;42:75-90.

35. Hoes JN, van der Goes MC, van Raalte DH, et al. Glucose tolerance, insulin sensitivity and $\beta$-cell function in patients with rheumatoid arthritis treated with or without low-to-medium dose glucocorticoids. Ann Rheum Dis 2011;70:1887-94

36. von Knorring J. Treatment and prognosis in polymyalgia rheumatica and temporal arteritis. A ten-year survey of 53 patients. Acta Med Scand 1979;205:429-35.

37. Godeau P, Aubert L, Guillevin L, et al. [Clinical aspects, outcome and prognosis of Horton's disease. Retrospective study of 47 cases]. Ann Med Interne 1982;133:393-400.

38. Chuang TY, Hunder GG, Ilstrup DM, et al. Polymyalgia rheumatica: a 10-year epidemiologic and clinical study. Ann Intern Med 1982;97:672-80.

39. Behn AR, Perera T, Myles AB. Polymyalgia rheumatica and corticosteroids: how much for how long? Ann Rheum Dis 1983;42:374-8.

40. Gouet D, Marechaud R, Alcalay M, et al. Survival in giant cell arteritis: a 14-year survey of 87 patients. J Rheumatol 1985;12:1209-10.

41. Andersson R, Malmvall BE, Bengtsson BA. Long-term corticosteroid treatment in giant cell arteritis. Acta Med Scand 1986;220:465-9.

42. Delecoeuillerie G, Joly P, Cohen de Lara A, et al. Polymyalgia rheumatica and temporal arteritis: a retrospective analysis of prognostic features and different corticosteroid regimens (11 year survey of 210 patients). Ann Rheum Dis 1988;47:733-9.

43. Nesher G, Sonnenblick M, Friedlander Y. Analysis of steroid related complications and mortality in temporal arteritis: a 15-year survey of 43 patients. J Rheumatol 1994;21:1283-6.

44. Gabriel SE, Sunku J, Salvarani C, et al. Adverse outcomes of antiinflammatory therapy among patients with polymyalgia rheumatica. Arthritis Rheum 1997;40:1873-8.

45. Proven A, Gabriel SE, Orces C, et al. Glucocorticoid therapy in giant cell arteritis: duration and adverse outcomes. Arthritis Rheum 2003;49:703-8.

46. Hutchings A, Hollywood J, Lamping DL, et al. Clinical outcomes, quality of life, and diagnostic uncertainty in the first year of polymyalgia rheumatica. Arthritis Rheum 2007;57:803-9.

47. Salvarani C, Macchioni P, Manzini C, et al. Infliximab plus prednisone or placebo plus prednisone for the initial treatment of polymyalgia rheumatica: a randomized trial. Ann Intern Med 2007:146:631-9.

48. Cimmino MA, Salvarani C, Macchioni P, et al. Long-term follow-up of polymyalgia rheumatica patients treated with methotrexate and steroids. Clin Exp Rheumatol 2008;26:395-400.

49. Schmidt WA, Moll A, Seifert A, et al. Prognosis of large-vessel giant cell arteritis. Rheumatology 2008;47:1406-8.

50. Dasgupta B, Hutchings A, Hollywood J, et al. Disease activity, quality of life and adverse events in the first two years of polymyalgia rheumatica. Rheumatology 2009;48:i17.

51. Khalifa M, Karmani M, Jaafoura NG, et al. Epidemiological and clinical features of giant cell arteritis in Tunisia. Eur J Intern Med 2009;20:208-12.

52. Martinez-Lado L, Calviño-Díaz C, Piñeiro A, et al. Relapses and recurrences in giant cell arteritis: a population-based study of 
patients with biopsy-proven disease from northwestern Spain. Medicine 2011;90:186-93.

53. Mazzantini M, Torre C, Miccoli M, et al. Adverse events during longterm low-dose glucocorticoid treatment of polymyalgia rheumatica: a retrospective study. J Rheumatol 2012;39:552-7.

54. Dunstan E, Lester SL, Rischmueller M, et al. Epidemiology of biopsy-proven giant cell arteritis in South Australia. Intern Med $J$ 2014;44:32-9.

55. Alba MA, García-Martínez A, Prieto-González S, et al. Relapses in patients with giant cell arteritis: prevalence, characteristics, and associated clinical findings in a longitudinally followed cohort of 106 patients. Medicine 2014;93:194-201.
56. Seror R, Baron G, Hachulla E, et al. Adalimumab for steroid sparing in patients with giant-cell arteritis: results of a multicentre randomised controlled trial. Ann Rheum Dis 2014;73:2074-81.

57. Muller G, Devilliers H, Besancenot JF, et al. Giant cell arteritis (Horton's disease) in very elderly patients aged 80 years and older: A study of 25 cases. Geriatr Gerontol Int 2016;16:679-85.

58. Carbonella A, Berardi G, Petricca L, et al. Immunosuppressive therapy (methotrexate or cyclophosphamide) in combination with corticosteroids in the treatment of giant cell arteritis: comparison with corticosteroids alone. J Am Geriatr Soc 2016;64:672-374. 